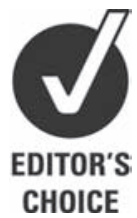

CHOICE

\title{
Prevalence of radiological signs of femoroacetabular impingement in patients presenting with long-standing adductor-related groin pain
}

\author{
A Weir, ${ }^{1}$ R J de Vos, ${ }^{1}$ M Moen, ${ }^{2}$ P Hölmich, ${ }^{3} \mathrm{~J} \mathrm{~L} \mathrm{Tol}{ }^{1}$
}

\begin{abstract}
${ }^{1}$ Sports Medicine Department The Hague Medical Centre, Antoniushove Hospital, Leidschendam, The Netherlands

2Department of Sports Medicine, Rijnland Hospital, Leiderdorp, The Netherlands ${ }^{3}$ Department of Orthopaedic Surgery, Amager Hospital, Faculty of Health Sciences, University of Copenhagen, Denmark
\end{abstract}

\section{Correspondence to} Dr A Weir, Sports Medicine Department, The Hague Medical Centre Antoniushove, P0 Box 411, Burgemeester Banninglaan 1, $2260 \mathrm{AK}$

Leidschendam,

The Netherlands;

a.weir@mchaaglanden.nl

Accepted 03 July 2009 Published Online First 11 June 2010

\begin{abstract}
Objective A decreased range of motion (ROM) of the hip joint is known to predispose to athletic groin injury. Femoroacetabular impingement (FAl) of the hip leads to a reduced ROM. This study examined the prevalence of radiological signs of $\mathrm{FAl}$ in patients presenting with longstanding adductor-related groin pain (LSARGP).

Design Prospective case series.

Setting Outpatient Sports Medicine Department.

Patients 34 athletes with LSARGP defined as pain on palpation of the proximal insertion of adductor muscle and a painful, resisted adduction test.

Assessment A clinician blinded to the results of the radiological assessment performed a physical examination: iliopsoas length, hip ROM and anterior hip impingement test. Anteroposterior pelvic radiographs were examined by a second blinded clinician for the presence of: pistol grip deformity, centrum-collumdiaphyseal angle, femoral head neck ratio, coxa profunda, protrusio acetabuli, lateral centre edge angle, acetabular index and cross-over sign.

Results The prevalence of radiological signs of FAl was $94 \%(64 / 68)$. The mean number of radiological signs in hips with LSARGP was 1.84 (range $0-4$, SD 1.05) and 1.96 (range $0-5, S D 1.12$ ) in asymptomatic groins $(p=0.95)$. The anterior hip impingement test was positive in nine cases. There was no relationship with the number of radiological signs $(p=0.95)$. There was no correlation between hip ROM and the number of radiological signs $(p=0.37)$.

Conclusion Radiological signs of FAl are frequently observed in patients presenting with LSARGP. Clinicians should be aware of this fact and the possible lack of correlation when assessing athletes with groin pain.
\end{abstract}

Long-standing adductor-related groin pain (LSARGP) is common in sports such as soccer and rugby involving cutting and kicking. The annual frequency of groin injuries is $8 \%$ to $18 \%$ in football. ${ }^{12}$ LSARGP can be difficult to treat, and there is a lack of consensus as to the diagnostic criteria that apply in groin pain. Many authors have noted that multiple diagnoses are common. ${ }^{3-5 a}$ LSARGP is a diagnostic term used to describe pain at the proximal attachment of the adductor muscles on the pubic bone on sporting activities. ${ }^{5 a}$ The pain can be felt on palpating the proximal attachment of the adductor muscles and can de reproduced when resisted hip adduction is performed. It is termed long standing when symptoms have been present for more than 2 months. ${ }^{5 b}$ It has long been noted that patients with long-standing groin pain appeared to have a reduced hip joint range of motion (ROM). ${ }^{6}$ Recent prospective studies confirmed this association. ${ }^{7} 8$ The cause of this reduced ROM is unclear. ${ }^{7}$ One possible explanation may be that the reduced ROM could be due to a hip disorder.

Femoroacetabular impingement (FAI) is a hip condition which is considered by some authors to be due to subtle developmental disorders of the hip. ${ }^{9}$ FAI is caused by abnormal contact between the femur and the acetabulum. It is clinically characterised by a reduced hip joint ROM and pain when the hip impingement test is performed..$^{10}$ FAI has two subtypes: cam and pincer impingement. In cam impingement, there is an abnormality of the femoral head or neck, and pincer impingement occurs when the acetabulum is abnormal. At the time of writing, at least eight different radiological signs have been reported to show the presence of FAI. ${ }^{11-15}$

The natural history of this condition is unknown, although population studies are being performed to evaluate this. ${ }^{9}$ The current suggested treatment for FAI is conservative with activity modification, analgesia of anti-inflammatories and possibly modification of technique. ${ }^{10}$ If conservative therapy is unsuccessful, then surgical treatment with correction of the abnormal shape of the femur (cam impingement), acetabulum (pincer impingement) or both can be performed. ${ }^{9} 11$

This study aims to examine the relationship between LSARGP and FAI. First, the clinical findings of the hip joint ROM, the hip impingement test and the length of the iliopsoas muscle were examined in athletes presenting with LSARGP. Second, the prevalence of radiological signs of FAI in these athletes was examined. Third, the relationship between physical and radiological findings of FAI was examined.

\section{METHODS \\ Patients}

Patients with groin pain were seen at the Sports Medicine Department of a large general hospital. Patients were referred by their general practitioner or a physical therapist. The diagnosis was made based on history and a standardised clinical examination. ${ }^{16}$ All patients who presented were included in the study after they gave their informed consent. The regional medical ethics committee approved the study. The type of sport, frequency of sports activities and Tegner activity score were recorded. The inclusion and exclusion criteria are shown in table 1. 
Table 1 Inclusion and exclusion criteria

\begin{tabular}{ll}
\hline Inclusion criteria & Exclusion criteria \\
\hline $\begin{array}{l}\text { Groin pain for at least 2 months } \\
\begin{array}{l}\text { Pain located at the proximal insertion } \\
\text { of the adductor muscles on the } \\
\text { pubic bone }\end{array}\end{array}$ & $\begin{array}{l}\text { Palpable inguinal or femoral hernia or pain } \\
\text { felt above the conjoint tendon } \\
\text { Clinical signs or symptoms of prostatitis } \\
\text { or urinary tract infection }\end{array}$ \\
$\begin{array}{l}\text { Pain felt at the proximal insertion } \\
\text { of the adductor muscles on the pubic } \\
\text { bone when performing resisted } \\
\text { adduction } \\
\begin{array}{l}\text { Groin pain during or after sporting } \\
\text { activities }\end{array}\end{array}$ & $\begin{array}{l}\text { Back pain felt from T10 to L5 } \\
\text { Clinical suspicion of a nerve entrapment } \\
\text { syndrome of the ilioinguinal, genitofemoral } \\
\text { or lateral cutaneus nerves } \\
\text { Kne 18-50 years }\end{array}$ \\
\hline
\end{tabular}

\section{Physical examination}

All patients were examined by a single experienced sports medicine physician (AW) blinded to the results of the radiological assessment using a standard protocol and the physical examination that has been shown to be reliable. ${ }^{16}$ The iliopsoas length was assessed using the modified Thomas test as reported by Hölmich et al. ${ }^{16}$ The iliopsoas was considered to be shortened when the thigh was horizontal or above horizontal. The length was considered to be normal when the thigh was below horizontal.

Hip joint ROM was measured using a goniometer with the patient lying supine with the knee and hip flexed to $90^{\circ}$, which has been shown to be reliable. ${ }^{17}$ The internal and external rotation was measured separately, and the total rotation was calculated by adding the ROM for internal and external rotation.

The anterior hip impingement test (also called the flexioninternal rotation-adduction impingement test) was performed with the patient lying supine. The hip is passively flexed to $90^{\circ}$, and progressive internal rotation and adduction are then applied until an end point is reached. ${ }^{11}$ The test is positive if the groin pain is reproduced.

\section{Radiological evaluation}

In all patients, a plain anteroposterior radiograph of the pelvis was obtained. The film focus distance was $1.2 \mathrm{~m}$, and the central beam was directed to the midpoint between a line connecting the both anterosuperior iliac spines and the superior border of the symphisis. ${ }^{18}$ Digitalised radiographs were evaluated using a computer imaging system (Magic View; Fa.Siemens, Munich, Germany). All measurements were performed by a single experienced examiner who was blinded to the clinical findings.

The radiographs were assessed for signs of cam impingement using the following three signs: pistol grip deformity defined as a flattening of the usually concave surface of the lateral aspect of the femoral head. ${ }^{12} 13$ The centrum-collumdiaphyseal (CCD) angle was measured. A CCD angle of less than $125^{\circ}$ has been reported to show cam impingement. ${ }^{13}$ The femoral head neck index of Heymann and Herndon was calculated. ${ }^{14}$ The normal range for the femoral head neck index is 150-190 and was scored as being abnormal when it was less than 150 .

Pincer impingement was assessed using the following five signs: Coxa profunda was said to be present when the ilioischial line touches or overlaps medially with the floor of the fossa acetabuli. ${ }^{13}$ Protrusio acetabuli is said to be present when the head of the femur overlaps medially with the ilioischial line. ${ }^{13}$ The lateral centre edge angle is the angle formed by a
Table 2 Criteria used to assess the presence of femoroacetabular impingement on anteroposterior radiograph

\begin{tabular}{ll}
\hline Type of impingement & Sign \\
\hline Cam & Pistol grip deformity ${ }^{1213}$ \\
Cam & CCD angle $<125^{\circ 13}$ \\
Cam & Femoral head neck index $<150^{14}$ \\
Pincer & Coxa profunda ${ }^{13}$ \\
Pincer & Protrusio acetabuli13 \\
Pincer & Lateral centre edge angle $>39^{\circ 19}$ \\
Pincer & Acetabular index $\leq 0^{13}$ \\
Pincer & Cross-over sign \\
\hline
\end{tabular}

vertical line and a line connecting the femoral head centre with the lateral edge of the acetabulum. An angle of less than $25^{\circ}$ defines a dysplasia. ${ }^{15}$ An angle greater than $39^{\circ}$ is an indicator for acetabular overcoverage. ${ }^{19}$ The acetabular index is the angle between a horizontal line and a line connecting the medial point of the sclerotic zone with the lateral centre of the acetabulum. A value of $0^{\circ}$ or a negative value is said to be a sign of pincer impingement. ${ }^{13}$ In a normal acetabulum, the anterior rim line projects medially to the posterior wall due to anteversion. ${ }^{20}$ Focal over coverage of the anterosuperior acetabulum was assessed using the cross-over sign. The cross-over sign is present when the line of the anterior acetabular rim is lateral to the line of the posterior acetabular rim in the cranial part of the acetabulum..$^{13}$

In total, each hip was radiologically assessed for eight different signs for the presence of femoroacetabular impingement. These criteria are summarised in table 2.

\section{Statistical analysis}

Statistical analysis was performed using SPSS (version 14.0; 2005 SPSS, Chicago, Illinois, USA). Descriptive statistics were used for the patient demographics and the radiological score. The results are presented as means with SD when the data were parametric and medians with inter-quartile ranges (IOR) when the data were non-parametric. The relationship between variables was examined with the Spearman test, the $\chi^{2}$ test or the $t$ test according to the type of variable examined.

\section{RESULTS}

\section{Patient demographics}

Between September 2006 and June 2007, 44 consecutive patients were seen with groin pain. Six patients were excluded because they had pain above the conjoined tendon or a palpable inguinal hernia. Four patients were excluded as they also had current lower back pain.

Thirty-four patients (68 groins) were suitable for inclusion and were assessed. There were 10 patients with bilateral pain, 13 with right-sided pain and 11 with left-sided pain. This meant that of the 68 groins evaluated, 44 had LSARGP. The patient demographics for the patients included in the study were as follows: the average age was 30 (range18-45, SD 8.3) years. The mean body mass index was 24.3 (range 20-29, SD $2.2) \mathrm{kg} / \mathrm{m}^{2}$. The median duration of symptoms was 22 (range 8-250, IOR 36) weeks with an average duration of abstinence from sport of 15 (range $0-130$, SD 24) weeks. The patients were involved in the following sports: $23(68 \%)$ soccer, $2(6 \%)$ rugby, $2(6 \%)$ distance running, $2(6 \%)$ field hockey and $5(16 \%)$ other sports. Frequency of sports activities was: $4(12 \%)$ once or twice weekly, 23 (68\%) three to four times weekly and 7 $(21 \%)$ more than five times a week. The mean Tegner activity 
Table 3 Prevalence of abnormal radiological signs

\begin{tabular}{lc}
\hline Sign & Number of times observed in $\mathbf{6 8}$ hips \\
\hline Pistol grip deformity & $27(40 \%)$ \\
CCD angle $<125^{\circ 12}$ & $2(3 \%)$ \\
Femoral head neck index $<150^{13}$ & 0 \\
Coxa profunda & $23(34 \%)$ \\
Protrusio acetabuli' & 0 \\
Lateral centre edge angle $>39^{\circ 15}$ & $20(29 \%)$ \\
Acetabular index $\leq 0^{12}$ & $31(46 \%)$ \\
Cross-over sign & $25(37 \%)$ \\
\hline
\end{tabular}

Table 4 Number of radiological signs per hip

\begin{tabular}{lc}
\hline Number of radiological signs & Number of hips (total=68) \\
\hline 0 & $4(6 \%)$ \\
1 & $18(27 \%)$ \\
2 & $26(38 \%)$ \\
3 & $12(17 \%)$ \\
4 & $6(9 \%)$ \\
5 & $2(3 \%)$ \\
\hline
\end{tabular}

score was 8.74 (range 7-10, SD 0.62). There were no dropouts or incomplete datasets.

\section{Physical examination}

The iliopsoas was noted to be shortened in 40\% (27/68) of all groins. The average ROM in the hip joint was 22 (SD 12) degrees of internal rotation, and 60 (SD 18) degrees of total rotation. The hip joint total range of rotation or the range of internal rotation was not reduced in hips where adductorrelated groin pain was felt when compared to hips where no groin pain was felt $(p=0.69, p=0.79)$. The anterior hip impingement test was positive in nine hips $(13 \%)$, all of which were symptomatic for LSARGP.

There was no significant relationship between the iliopsoas being shortened and a painful hip impingement test $(\mathrm{p}=0.68)$. The ROM in the nine hips with a positive anterior hip impingement test $\left(56^{\circ}\right)$ was not significantly different from the 59 hips with a negative test $\left(60^{\circ}, \mathrm{p}=0.53\right)$.

\section{Radiological examination}

In total, there were 128 abnormal radiological signs observed in the 68 hips of the 34 patients with LSARGP. The prevalence of different signs observed is shown in table 3 .

The prevalence of radiological signs for FAI was $94 \%$ with only four hips $(6 \%)$ without any signs of FAI. The number of signs for each hip is shown in table 4.

There was no association between the number of radiological signs and the anterior hip impingement test being positive $(p=0.95)$. In fact, the two hips with the highest number of radiological signs of FAI had a negative anterior hip impingement test. The mean number of radiological signs in sides with LSARGP ( $n=44 ; 1.84$, range $0-4$, SD 1.05) was not significantly different from the number in the asymptomatic hips $(\mathrm{n}=24 ; 1.96$, range $0-5, \mathrm{SD} 1.12, \mathrm{p}=0.95)$. There was no correlation between hip ROM and the number of radiological signs $(\mathrm{p}=0.37)$.

\section{DISCUSSION}

In this study, there was a high prevalence of radiological signs of FAI in athletes presenting with LSARGP. Ninety-four per cent $(64 / 68)$ of the hips assessed showed radiological signs of FAI. The fact that only $6 \%$ of the hips were found to be radiologically normal is concerning, and it raises a number of questions. In the literature, at the time of writing, eight different signs were found that have already been reported to show the presence of FAI. There are a growing number of publications on the different signs that can be observed on additional imaging investigations for making the diagnosis of FAI. As the number of possible signs used to make the diagnosis increases, the prevalence of the disorder will also increase. At present, there is no clear consensus as to when the diagnosis of FAI can be made, and a gold standard is missing. This is a problem in clinical practice and has been noted by other authors. ${ }^{21}$ Many studies reporting on the treatment of patients with FAI have no clear inclusion criteria. ${ }^{22} 23$ This may be due to bias as all the patients did in fact have groin pain. There are no studies at present that report the prevalence of abnormalities in asymptomatic populations. Ganz et al have reported that a study is in progress, and these results will be welcome to enable the definition of normal values. ${ }^{9}$ This may help to create clear diagnostic criteria for FAI which can serve as a gold standard for making the diagnosis. At the present time, it is unclear as to whether hips with radiological signs of FAI but no pain should be diagnosed as having FAI or not.

There was no association between a positive anterior hip impingement test and reduced ROM or a higher number of radiological signs of FAI. The anterior hip impingement test that involves moving the hip into flexion, internal rotation and adduction is cited in many papers as being positive in FAI. In this study, nine hips (13\%) had pain in the groin on performing the test. It could be argued that these nine patients all have FAI as they all also had at least one radiological abnormality. They did, however, present with pain located at the proximal insertion of the adductor muscles on the pubic bone and had recognisable tenderness on palpation. This would suggest that their primary pain may be located in the soft tissues and may be of extra-articular origin. These may then be false-positive tests. Recent research on the reliability of the anterior hip impingement test showed that it had a low reliability $(\kappa=0.58)$ when this was examined in a population of patients with different intraarticular hip joint problems. ${ }^{24}$ In this study, 70 patients with a variety of hip joint conditions (of which 48 were diagnosed with FAI) were examined by an orthopaedic surgeon and a physical therapist. They found the test to be positive in 57 patients suggesting that in some cases, the test was false positive.

To our knowledge, the validity has not been examined in patients with extra-articular causes of groin pain. The movement performed during the test could also cause movement and stress at the pubic symphisis, which is one of the possible sources of pain in patients with chronic adductor-related groin pain. ${ }^{25}$ The motion may also twist and compress the iliopsoas muscle which has been reported to be a secondary source of pain in many patients presenting with adductor-related groin pain. ${ }^{5 a}$ Until the validity of the anterior hip impingement test has been further examined, it should be interpreted with caution.

The subject of differential diagnosis in athletes presenting with chronic groin pain has long been a topic of interest. Many authors have reported multiple entities in patients presenting with long-standing groin pain. ${ }^{35 a}$ The prevalence of different conditions varies greatly between the studies. In one study of 203 athletes presenting with groin pain of more than 2 months, only one hip problem was diagnosed. ${ }^{5 a}$ In this study, adductor pain was the primary diagnosis in $58 \%$ of cases. In a different study examining 218 athletes presenting with groin pain, the hip was the primary source of pain in $46 \%$ of 
all cases. ${ }^{26}$ While this may be due to differences in referral patterns that would seem unlikely, considering that the study with the far lower prevalence of hip disorders was performed by an orthopaedic surgeon, the study with the high prevalence was performed by a sports physician. It is hypothesised that the differences may well be due to varying diagnostic criteria. At present, there are no generally accepted diagnostic criteria for the different entities causing groin pain. This is in part due to a lack of understanding about the underlying pathology and partly due to the confusing scientific taxonomy surrounding groin pain. It is clear that there is great need for clear diagnostic criteria in cases of groin pain and that these criteria should also cover intra-articular hip pathologies.

As mentioned above, multiple diagnoses can coexist, and indeed, Bradshaw et al ${ }^{26}$ reported that 10 of the 218 athletes did have coexisting osteitis pubis and hip joint pathology, although these conditions are not further defined.

It may also be that the relationship between the hip joint and chronic adductor-related groin pain is more complex. Prospective studies have shown that athletes with a reduced hip joint ROM have a higher risk of developing chronic groin injury. It was hypothesised that the reduced ROM may cause increased loading and mechanical stress on the pubic symphisis and surrounding structures. ${ }^{7}$ In previous studies, it was stated that it was unclear as to which structures limit the hip joint range of rotational motion. ${ }^{7}$ A possible explanation may be that an underlying FAI predisposes to chronic groin injury through a reduced ROM. Other authors have suggested that inflammation as a response to loading may cause capsular tightness leading to a reduction of ROM. ${ }^{27}$ This mechanism has been noted to cause a restriction of the range of shoulder rotation in overhead athletes. ${ }^{28}$ As this study is not prospective, no cause-effect relationship can be established, and future studies will be necessary to examine this further.

A possible shortcoming of this is the fact that the ROM of the hip joint was measured once using a goniometer with the hip in $90^{\circ}$ of flexion. Although the use of a single measurement has been shown to be reliable, ${ }^{17}$ it has also been suggested that multiple measures should be taken for joints with a large ROM. ${ }^{29}$ The choice to measure the hip joint in flexion has also been noted by others to be questionable as most loading during sports activities occurs at a much lesser degree of flexion. ${ }^{7}$

Future studies are needed to provide clear diagnostic criteria for causes of groin pain and to examine the relationships between these pathologies.

\section{CONCLUSION}

Radiological signs of femoroacetabular impingement are frequently observed in patients presenting with LSARGP. Radiological findings of hip impingement are often present without the anterior hip impingement test being painful. The anterior hip impingement test may not be specific for femoroacetabular impingement. Clear diagnostic criteria for femoroacetabular impingement and other causes of groin pain are needed.

\section{Competing interest None.}

Patient consent Obtained.

Ethics approval This study was conducted with the approval of the Regional board metc zuid west Holland.

Provenance and peer review Not commissioned; externally peer reviewed.

\section{REFERENCES}

1. Ekstrand J, Hilding J. The incidence and differential diagnosis of acute groin injuries in male soccer players. Scand J Med Sci Sports 1999;9:98-103.

2. Hölmich P. Adductor related groin pain in athletes. Sports Med Arthrosc Rev 1998;5, 285-91.

3. Ekberg 0, Persson NH, Abrahamsson PA, et al. Longstanding groin pain in athletes. A multidisciplinary approach. Sports Med 1988;6:56-61.

4. Lovell G. The diagnosis of chronic groin pain in athletes: a review of 189 cases. Aust J Sci Med Sport 1995;27:76-9.

5a. Hölmich P. Long-standing groin pain in sportspeople falls into three primary patterns, a "clinical entity" approach: a prospective study of 207 patients. $B r \mathrm{~J}$ Sports Med 2007;41:247-52; discussion 252.

5b. Hölmich P, Uhrskou P, Ulnits L, et al. Effectiveness of active physical training as treatment for long-standing adductor-related groin pain in athletes: randomised trial. Lancet 1999;353:439-43.

6. Williams JG. Limitation of hip joint movement as a factor in traumatic osteitis pubis. Br J Sports Med 1978;12:129-33.

7. Verrall GM, Slavotinek JP, Barnes PG, et al. Hip joint range of motion restriction precedes athletic chronic groin injury. J Sci Med Sport 2007;10:463-6.

8. Ibrahim A, Murrell GA, Knapman P. Adductor strain and hip range of movement in male professional soccer players. J Orthop Surg (Hong Kong) 2007;15:46-9.

9. Ganz R, Leunig M, Leunig-Ganz K, et al. The etiology of osteoarthritis of the hip: an integrated mechanical concept. Clin Orthop Relat Res 2008;466:264-72.

10. Keogh MJ, Batt ME. A review of femoroacetabular impingement in athletes. Sports Med 2008;38:863-78.

11. Ganz R, Parvizi J, Beck M, et al. Femoroacetabular impingement: a cause for osteoarthritis of the hip. Clin Orthop Relat Res 2003;112-20.

12. Siebenrock KA, Wahab KH, Werlen S, et al. Abnormal extension of the femoral head epiphysis as a cause of cam impingement. Clin Orthop Relat Res 2004; 54-60.

13. Tannast M, Siebenrock KA, Anderson SE. Femoroacetabular impingement: radiographic diagnosis - what the radiologist should know. AJR Am J Roentgenol 2007; 188:1540-52

14. Jäger M, Wild $A$, Westhoff $B$, et al. Femoroacetabular impingement caused by a femoral osseous head-neck bump deformity: clinical, radiological, and experimental results. J Orthop Sci 2004;9:256-63.

15. Murphy SB, Ganz R, Müller ME. The prognosis in untreated dysplasia of the hip. A study of radiographic factors that predict the outcome. J Bone Joint Surg Am 1995; 77:985-9.

16. Hölmich P, Hölmich LR, Bjerg AM. Clinical examination of athletes with groin pain: an intraobserver and interobserver reliability study. Br J Sports Med. 2004;38:446-51.

17. Boone DC, Azen SP, Lin CM, et al. Reliability of goniometric measurements. Phys Ther 1978;58:1355-90.

18. Tannast M, Zheng G, Anderegg C, et al. Tilt and rotation correction of acetabular version on pelvic radiographs. Clin Orthop Relat Res 2005;438:182-90.

19. Tönnis D, Heinecke A. Acetabular and femoral anteversion: relationship with osteoarthritis of the hip. J Bone Joint Surg Am 1999;81:1747-70.

20. Siebenrock KA, Kalbermatten DF, Ganz R. Effect of pelvic tilt on acetabular retroversion: a study of pelves from cadavers. Clin Orthop Relat Res 2003;241-8.

21. Standaert CJ, Manner PA, Herring SA. Expert opinion and controversies in musculoskeletal and sports medicine: femoroacetabular impingement. Arch Phys Med Rehabil 2008;89:890-3.

22. Peters CL, Erickson JA. Treatment of femoro-acetabular impingement with surgical dislocation and débridement in young adults. J Bone Joint Surg Am 2006;88:1735-41.

23. Beck M, Leunig M, Parvizi J, et al. Anterior femoroacetabular impingement: part II. Midterm results of surgicaltreatment. Clin Orthop Relat Res 2004;418:67-73.

24. Martin RL, Sekiya JK. The interrater reliability of 4 clinical tests used to assess individuals withmusculoskeletal hip pain. J Orthop Sports Phys Ther 2008;38:71-7.

25. Jansen JA, Mens JM, Backx FJ, et al. Diagnostics in athletes with long-standing groin pain. Scand J Med Sci Sports 2008;18:679-90.

26. Bradshaw CJ, Bundy M, Falvey E. The diagnosis of longstanding groin pain: a prospective clinical cohort study. Br J Sports Med 2008;42:551-4.

27. Verrall GM, Hamilton IA, Slavotinek JP, et al. Hip joint range of motion reduction in sports-related chronic groin injury diagnosed as pubic bone stress injury. J Sci Med Sport 2005;8:77-84.

28. Bach HG, Goldberg BA. Posterior capsular contracture of the shoulder. J Am Acad Orthop Surg 2006;14:265-77.

29. Bovens AM, van Baak MA, Vrencken JG, et al. Variability and reliability of joint measurements. Am J Sports Med 1990;18:58-63. 